\title{
Clinical and Radiographic Evaluation of Cattle Tail before and after the Vaquejada Race
}

\author{
Raíssa Karolliny Salgueiro Cruz ${ }^{*}$, Maria Luiza Albuquerque Ribeiro², Juliano Sarmento Macedo², \\ Brunno Aguiar Ferreira², Marcelo Araújo Silva², Anaemília das Neves Diniz ${ }^{3}$, \\ Helena Emília Cavalcanti da Costa Cordeiro Manso ${ }^{4}$, Helio Cordeiro Manso Filho ${ }^{4}$
}

${ }^{1}$ Professor of the Veterinary Medicine course, Cesmac University Center (CESMAC), Maceió-AL, Brazil

${ }^{2}$ Veterinarian and Member of the Association of Veterinarians of Equidae and Bovids of Alagoas (AMVEBAL), Maceió-AL, Brazil

${ }^{3}$ Adjunct Professor at the Federal University of Alagoas, Maceió-AL, Brazil

${ }^{4}$ Equine Research Center, Federal Rural University of Pernambuco, Recife-PE, Brazil

Email: *raissa.cruz@cesmac.edu.br

How to cite this paper: Cruz, R.K.S., Ribeiro, M.L.A., Macedo, J.S., Ferreira, B.A., Silva, M.A., das Neves Diniz, A., da Costa Cordeiro Manso, H.E.C. and Filho, H. C.M. (2021) Clinical and Radiographic Evaluation of Cattle Tail before and after the Vaquejada Race. Open Journal of Veterinary Medicine, 11, 165-176.

https://doi.org/10.4236/ojvm.2021.116012

Received: April 23, 2021

Accepted: June 15, 2021

Published: June 18, 2021

Copyright $\odot 2021$ by author(s) and Scientific Research Publishing Inc. This work is licensed under the Creative Commons Attribution International License (CC BY 4.0).

http://creativecommons.org/licenses/by/4.0/

\begin{abstract}
The vaquejada race is a sport with animals which has the greatest socio-economic impact in Brazil and is responsible for generating an intense cultural and economic movement. However, this activity has been the subject of questions about well-being involving the environmental and mental comfort conditions offered to equine and cattle interactions. It is necessary to perform technical evaluations of the cattle involved on the basis of scientific study to better understand the processes of sport and, with this, promote their evolution on good welfare practices in the $21^{\text {st }}$ century. Therefore, to test the hypothesis that the use of the official rules of the vaquejada where cattle use a protective harness on the tail protects the cattle's tail from injuries in this region that compromise health. Before, during and after races, a study was developed that aimed to perform a general and radiological clinical evaluation in the proximal coccygeal region in cattle that ran in a modern cattle stall. Forty male bovines were evaluated (average: 2 year-old and $420 \mathrm{~kg}$ ). Oxen were subjected to clinical and radiological examination before and after racing with official rules. Results of the clinical and radiological evaluations performed by veterinarians, did not observe clinical occurrences before and after the races in the 40 cattle evaluated. The increase in heart and respiratory rates was a reflection of temporary management stressors, as the animals returned to the feeding/rumination/interaction pattern after running in the rest pen. The radiographic findings in the tail, represented by the reduction of the intervertebral space and areas of subcutaneous radiolucency, suggest technical artifacts derived from the manipulation of the tail for proper positioning to perform the tests in the condition of retention in the corral. The partial frac-
\end{abstract}


ture found by an evaluator showed signs of calcification and was accompanied by swelling in the soft tissue but without pain in the pre-run examination. It is concluded that the modern vaquejada race, which meets the official rules, is not related to the increase in lesions in the locomotor apparatus or other evaluated tissues, including the tail.

\section{Keywords}

Zebu, Physical Exercise, Locomotor, Health

\section{Introduction}

The vaquejada race is a typically Brazilian sport present in several regions of Brazil and practiced in a soft sand track with a minimum depth of not less than $40 \mathrm{~cm}$, forming a mattress in which two vaqueros mounted on Quarter-Horse horses have the objective of reaching the ox and pairing it among the horses, leading it to the score range demarcated area, where the cattle must be unbalanced and pull down at the sand mattress [1]. This sport has ethnographic, sociological, historical and mainly economic importance, where currently more than 1000 races are performed every year throughout Brazil.

The vaquejada modality has currently been questioned about environmental and psychological comfort conditions offered to the animals, as well as the possible injuries caused by the fall of the animal on the track, which may cause irreversible damage to the vertebral column, principally at the tails, of these animals. Vertebral fractures resulting from trauma can cause compression or destruction of the spinal canal, and animals may present with clinical signs, paresis and paralysis [2]. Conversely, limb and tail fractures have been described in old folk reports, however, since the implementation of the rules for the practice of the sport, ranging from weighing cattle, use of tail protectors and soft ground track model and officially recognized by the State Secretariat of Inspection and Control of Brazil [3] these situations have almost been eliminated and has impact over indicators of the animal welfare [4].

The physical examination can promote an accurate evaluation of the animal under different conditions and with ease of raising suspicion regarding the location of the fracture [5]. However, radiographic diagnosis can accurately confirm the clinical diagnosis and should be based on the observation of spinal alignment, size, shape and vertebral radiopacity [6] [7] [8]. There is nonscientific information suggesting the occurrence of spinal cord injuries, especially in the sacrococcygeal region of cattle used in vaquejada races, but to date, no scientific evidence has been found to confirm this fact in races that are subject to current official rules [1] [3]. Given these circumstances, to test the hypothesis that the use of official rules in a modern cowling does not cause injuries that compromise the health of cattle before, during and after the races, a project was developed that aims to perform a general and radiological clinical evaluation in the 
proximal coccygeal region in cattle that ran in modern vaquejada. The results of this study may contribute to improving the conditions of the animals involved in caving and provide information for the improvement of the current rules if necessary, meet the desires of our society in the 21 st century, and thus the sport obtains its social license to operate.

\section{Materials and Methods}

All experimental procedures were performed after approval by the Ethics Committee on the Use of Animals from the Cesmac University Center (04A/2016), in Maceió-AL, Brazil.

\subsection{Location of the Experiment, Animals and Farming System}

The study was conducted in an official park in the municipality of Pilar-AL $\left(09^{\circ} 35^{\prime} 50^{\prime \prime} \mathrm{S} ; 35^{\circ} 57^{\prime} 24^{\prime \prime} \mathrm{W}\right)$.

A total of 40 male Nellore oxen were used, with an average age of two years and an average weight of $420.0 \mathrm{~kg}$. The animals received the same food management, being raised on pasture of Brachiaria grass (Brachiaria decumbens) and supplemented with mineralized salt for cattle and water ad libitum. On the day before the evaluations, all the animals were moved to vaquajada field and housed in pens inside the cattle farm. In the park, there was shading, and the cattle had access to water, mineral salt and forage (chopped elephant grass, Pennisetum purpureurn Schum.) ad libitum. In these pens, the oxen were housed for 48 hours; 24 hours before and after the races, for clinical, behavioral and radiographic analyses. The cattle had already experienced management in these facilities and pens on different occasions previously, principally for health management practices.

The cattle were periodically managed for the sanitary control of parasitic diseases such as mandatory vaccinations, such as those for the prevention of clostridiosis (polyvalent SYMPTAN, Boehringer Ingelheim Animal Health, Campinas-SP) and foot-and-mouth disease (OurovacAftosa, OurofinoSaúde Animal, Cravinhos-SP)—Brazil) following the manufacturer's instructions.

\subsection{Clinical and Radiographic Evaluation in Cattle}

To perform this experiment, the cattle underwent clinical and radiographic examination on two occasions:

- Pre-race of the horse or M-1: animals were evaluated in the containment area ("brete") from the displacement of the rest pen to the containment area, where palpations of the lymph nodes and locomotor limbs were performed, followed by radiographic examinations and placement of the individual tails conical harness protector;

- Post-race or M-2: the arrival of the cattle in the containment area ("brete"), where the conical tail protector was removed, palpation of the lymph nodes and locomotor limbs was performed, followed by radiographic examinations 
and exit of the "brete" towards the corral of rest. In the resting pens, animals were monitored and evaluated clinically by the system of 5 domains [9] for a total of 48 hours, 24 hours before and 24 hours after the horse racing. All runs were performed on a standard track with soft sand for a length of 150 m.

In the clinical examination, the cattle were subjected to the following assessments: heart rate, respiratory rate, rectal temperature, mucosal color and skin characteristics (alopecia, lesions and ectoparasites), palpable lymph nodes (size, consistency, sensitivity and temperature). The locomotor system was also highlighted, with the animal being evaluated step by step to observe the presence of lameness, symmetry of the thoracic and pelvic limbs, increases in bone, joint and tendon volume, presence of wounds and bruises. Besides, in the evaluation of the 5 Domains, environmental, nutritional, health, behavioral and mental parameters were observed [9].

At the end of the radiographic examinations, the cattle were restrained at the brete, as described above, and radiographs were obtained in the latero-lateral and dorso-ventral positions, with the device positioned at a distance of $90 \mathrm{~cm}$ from the tail, using digital $\mathrm{Rx}$ equipment (Portable Orange $90 \mathrm{kV}$ with Scanner FCR system Fuji Film). To monitor the animals, in phases M-1 and M-2, were identified with a cattle wax marker (Raidl-Maxi, RAIDEX Gmbh, Dettingen/Erms, Germany). The conical tail protector (MMC Tails' Protectors LTDA, Teresina-PI, Brazil) was used individually following the manufacture orientations.

Digital radiographic images were recorded on a flash drive and converted into a jpeg format for individual analysis by three veterinarians who did not know the type of challenge in the cattle were subjected to and the knowledge of the results of the other two evaluators. The radiographic analysis followed the evaluation protocol that took into account the following items: morphological alteration, deviation, reduction of intervertebral space, subcutaneous radiolucency, cleft, complete or partial fracture, radiolucent image and loss of vertebral pattern. For the radiograph evaluations, three veterinarians with experience in radiographic examinations were used, where each veterinarian analyzed the radiographs of the tail of 40 cattle in two positions, totaling 80 images per veterinarian.

Results were tabulated in an Excel spreadsheet, and descriptive statistics were applied using the relative and absolute values and expressed as the mean \pm standard deviation.

\section{Results and Discussion}

Current study showed that, when the cattle were driven within the rules proposed by the MAPA [4], such as the use of cattle with minimum weights and use of individualized conical tail protectors and tracks with adequate tread, they could mitigate the possible injuries in different parts. Forty Nellore cattle were evaluated, and no clinical occurrences were observed before and after the runs, which was expected. Even the increase in heart and respiratory rate were reflec- 
tions of the action of temporary stressors, and this became clear with the return of the animals to the feeding/rumination/interaction/rest and mental pattern [9], adapted for Nellore oxen, after the races in the rest corral. The predominant radiographic findings were due to the handling of the tail in the containment pen to perform the radiographs and a single partial fracture found by an evaluator that already exists because it clinically demonstrated an increase in volume and no sensitivity in the area in pre-running period.

\subsection{Inspection and Palpation}

In the present study, when examining the skin, lymph nodes and mucous membranes, no changes were found in the parameters evaluated in the pre- and post-race cycles. The initial clinical evaluation also showed that the cattle used here were in good health, before any exercise. Also, the analysis of the locomotor system did not show changes in the parameters studied during the experimental period, and there were no abnormalities in the movements of getting up, after the fall, or in walking to the rest curral.

Lameness is sometimes detected in cattle after transport or when they are housed in unsanitary conditions. Lameness is the third most important disease in dairy cows, where cattle with a lower body score and inadequate housing system had a significant association with more limb injuries [10]. In contrast, in the beef industry, most episodes of lameness are observed in packing plants, and probably due to housing in commercial feedlots and transportation, and these authors showed that the most common location for lameness disease was the foot ( 85\%) [11]. However, Silveira et al (2018) [12] showed that beef farms in the Amazon region in Brazil, when they have inadequate facilities (corral and pasture), bovines have a significant amount of foot disorders, especially in the hind limbs. The cattle used in this research had a good body score and are housed in pasture. They walk from their pastures to the management corral for the vaquejada, and the type of accommodation and general management on the farms in the Northeast region of Brazil can contribute animal welfare. It should be noted that beef cattle in Brazil are largely raised and fattened on pasture until they are transported to slaughterhouses.

Also, in the thoracic and pelvic limbs, no asymmetry or increased bone, joint and tendon volume was detected, and there were no wounds or bruises during the pre- and post-run inspection. In addition, when the cattle were at rest, animals with suspended or dragged limbs or asymmetries resulting from joint displacements or fractures were not observed. Such observed evidence allows to interpret the efficiency of the soft sand mat in the range where the animals are placed, thus absorbing the impact of the fall and avoiding serious injuries to the animals. Upon palpation of the animals' bodies, only one animal showed an increase in volume in the dorsal region of the tail but was kept in the vaquejada test because it did not present pain, discomfort or any type of reaction when this area was palpated with some pressure. 


\subsection{Auscultation}

The mean values for heart rate (HR), respiratory rate (RR) and rectal temperature were $126 \pm 32.1 \mathrm{bpm}, 39 \pm 6.45 \mathrm{mpm}$ and $39.6^{\circ} \mathrm{C} \pm 0.7^{\circ} \mathrm{C}$, respectively, and reflect cattle movements. Between the rest pen and the retention cage on a sunny day in a tropical region, they were tachycardic and tachypneic according to the comparison with the parameters for animals at rest [13] [14]. The use of brete restraint for varying periods can also cause temporary stress and consequently excitation, which eventually results in considerable variations in respiratory and heart rates. Therefore, researchers should seek other ways of measuring these parameters, such as the use of cardiac monitors, which are minimally invasive and can store these clinical signs with confidence.

It is also known that Nellore cattle are better adapted to tropical conditions in Brazil; however, this group of animals may have more difficulties for handling when contained than European cattle. Therefore, it should be noted that cattle may exhibit changes in the heart and respiratory rate due to exposure to periods in the sun or when they are manipulated, which causes great excitement [15] [16]. However, when the stressor is removed, the animals should return to normal. In the present study, it was not possible to obtain the HR, RR and rectal temperature in the free animals in the rest pen, but in the inspection before and after the races observed them with normal feeding and drinking water, in addition to the animals ruminating and playing, which were excellent indicative of the welfare conditions of cattle when combined with other evaluations performed here, as described in the literature [4] [9].

\subsection{Radiographic Exams}

Evaluating the radiographic findings, it was observed that the presence of subcutaneous radiolucency (2.1\%) (Figure 1) and reduction of the intervertebral space (8.35\%) (Figure 2) were the most frequent in M-2; therefore, when studied the findings in $\mathrm{M}-1$ from $\mathrm{M}-2$, this higher frequency was maintained (Table 1). Radiographic finding, may suggest the presence of intervertebral disc diseases, when associated with pain, paresis or paralysis [17]. Post-race clinical examination was not able to detect pain or edema in the tail area of greater contact with the conical tail protector, which can rule out some type of injury in the radiographed area. It should also be noted that the highest frequency of these findings occurred at M-2, soon after the removal of the conical tail protector and when the cattle were excited by running, which made it difficult to contain it and its tail for radiographic examination and thus interfered with the quality of the images. Also, it is important to observe that Nellore have a typical behavior, which is very different from the European breeds.

Still, in the radiographic evaluations, it was observed that the item fracture/partial fracture (Figure 3 ) presented a low frequency $(<0.5 \%)$, when the total findings of this item in M-1 are removed, to those observed in M-2. Only one observation of partial fracture/fracture was observed in M-2, and it was precisely 


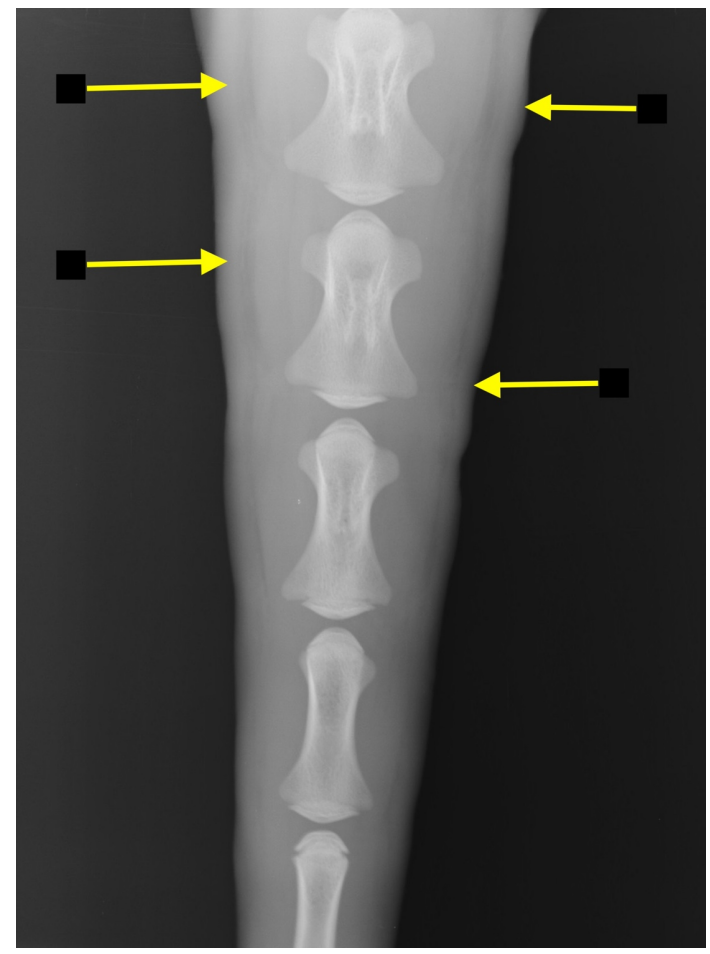

Figure 1. Example of the presence of subcutaneous radiolucency artifacts in the tail of Nellore cattle.

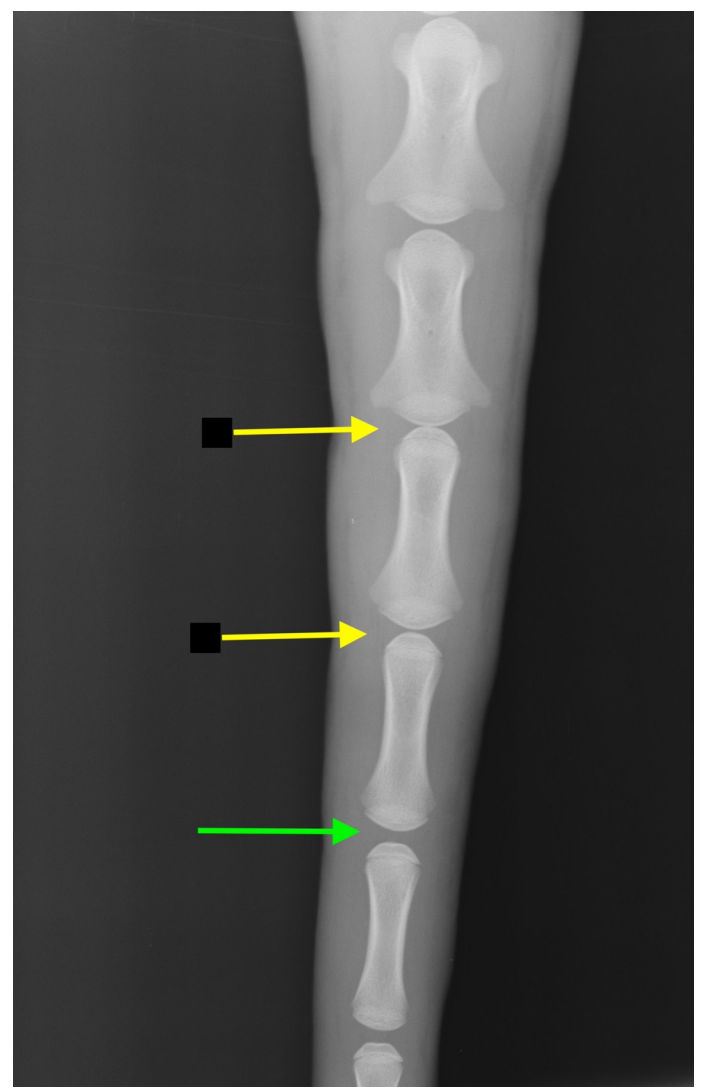

Figure 2. Example of artifacts caused by reduction of the intervertebral space in coccygeal vertebrae of Nellore cattle. 
Table 1. Frequency of radiographic * findings at the base of the tail of Nellore cattle, preand post-race of vaquejada in a soft sand track.

\begin{tabular}{cccc}
\hline \multirow{2}{*}{ Radiographic findings } & \multicolumn{3}{c}{ Total } \\
\cline { 2 - 4 } & $\mathbf{M}-\mathbf{1}^{\mathrm{T}}$ & $\mathbf{M - 2}^{\mathrm{T}}$ & $\mathbf{M}^{\mathrm{T}} \mathbf{2}^{\mathbf{M}-\mathbf{1}^{\mathrm{T}}}$ \\
\hline Morphological changes & $3(1.25 \%)$ & $3(1.25 \%)$ & 0 \\
Deviation & $3(1.25 \%)$ & $3(1.25 \%)$ & 0 \\
Reduction of intervertebral space & $17(7.10 \%)$ & $20(8.35 \%)$ & $3(1.25 \%)$ \\
Subcutaneous radiolucency & $1(0.42 \%)$ & $5(2.1 \%)$ & $4(1.67 \%)$ \\
Fissure & $3(1.25 \%)$ & $3(1.25 \%)$ & 0 \\
Fracture/partial fracture & $2(0.83 \%)$ & $3(1.25 \%)$ & $1(0.42 \%)$ \\
Radiolucent imaging & $1(0.42 \%)$ & $1(0.42 \%)$ & 0 \\
Loss of vertebral pattern & $2(0.83 \%)$ & $2(0.83 \%)$ & 0 \\
\hline
\end{tabular}

Observations: ${ }^{*} 80$ radiographic images were analyzed by each veterinarian $(n=3)$ in pre- and post-race, totaling 240 analysis per period of the race; $\mathrm{M}-1^{\mathrm{T}}$ : total of the findings and their frequencies in the pre-race; $\mathrm{M}-2^{\mathrm{T}}$ : total of the findings and their frequencies in the post-race.

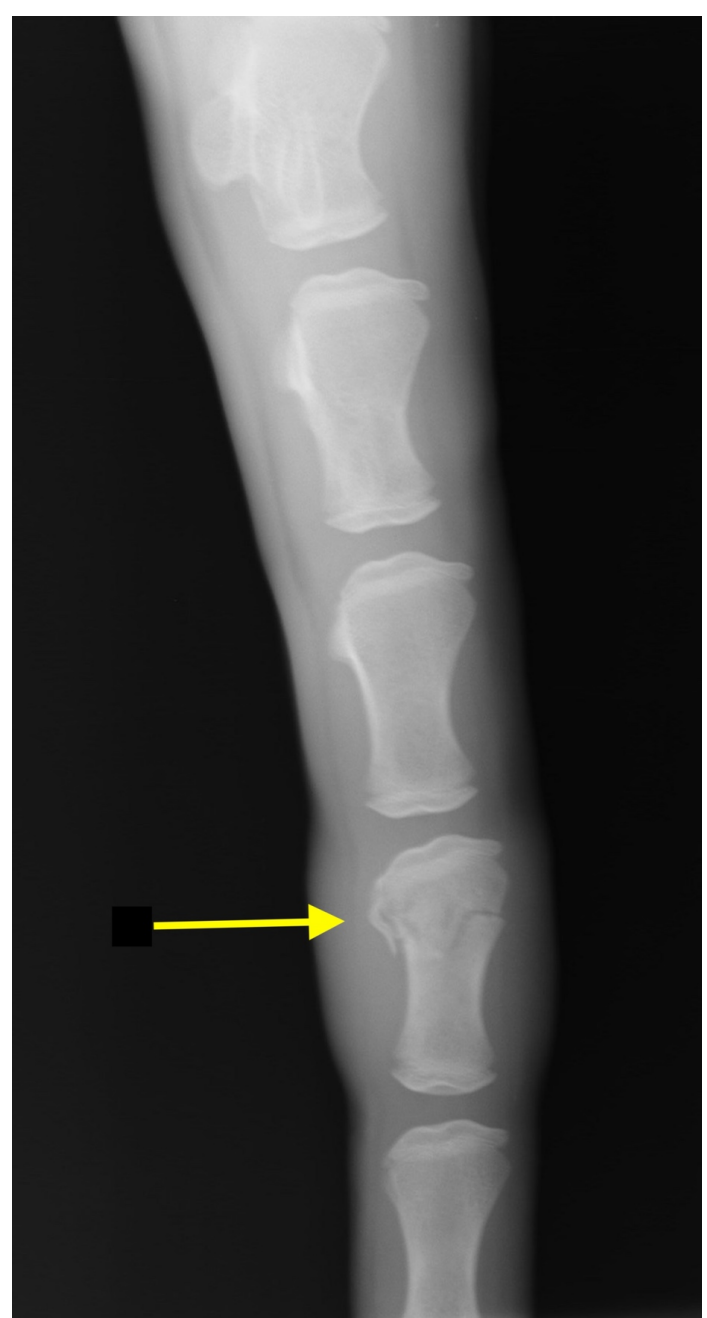

Figure 3. Example of incomplete fracture proximal partial texture with calcification in the coccygeal vertebrae accompanied by an increase in soft tissue volume in Nellore cattle. 
in the bovine that there was swelling in the tail but no pain on palpation. When evaluating the incomplete fractures (Figure 4), morphological changes (Figure 5 ) and deviation of the vertebral feed (Figure 6), there were no differences in the frequency between M-1 and M-2.

Different authors noted that fractures can involve any part of the spine, but the most common sites are the vertebral bodies, transverse processes and spinous processes. However, fractures and fissures in the tail bones, when they are more distal, can occur in management situations. Fractures can cause a sudden narrowing of the intervertebral disc space, and radiographically, the vertebrae may appear smaller than normal when a compressive fracture occurs. Dislocations or partial dislocations of the spine may occur with or without fractures, and sub-luxations may be accompanied by a decrease in the intervertebral space. These traumatic injuries to the spine and spinal cord often occur in veterinary and human medicine, leading to devastating sequelae, such as partial or complete loss of motor, sensory and visceral functions [18]. Some of these clinical signs are not related to a fracture of the tail bones, but pain with edema is frequent when these areas of the body are injured.

Consequences of the spinal cord trauma, depending on the injured segment,

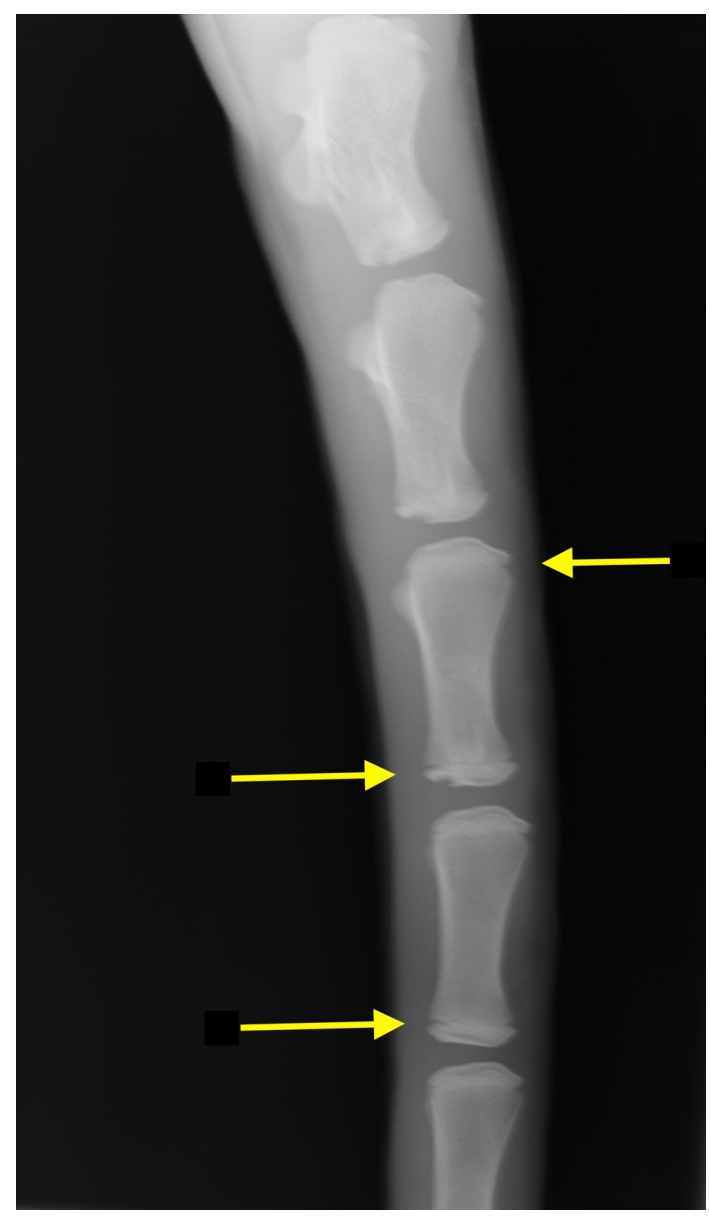

Figure 4. Example of the presence of a small distal cleft in coccygeal vertebrae of Nellore cattle. 


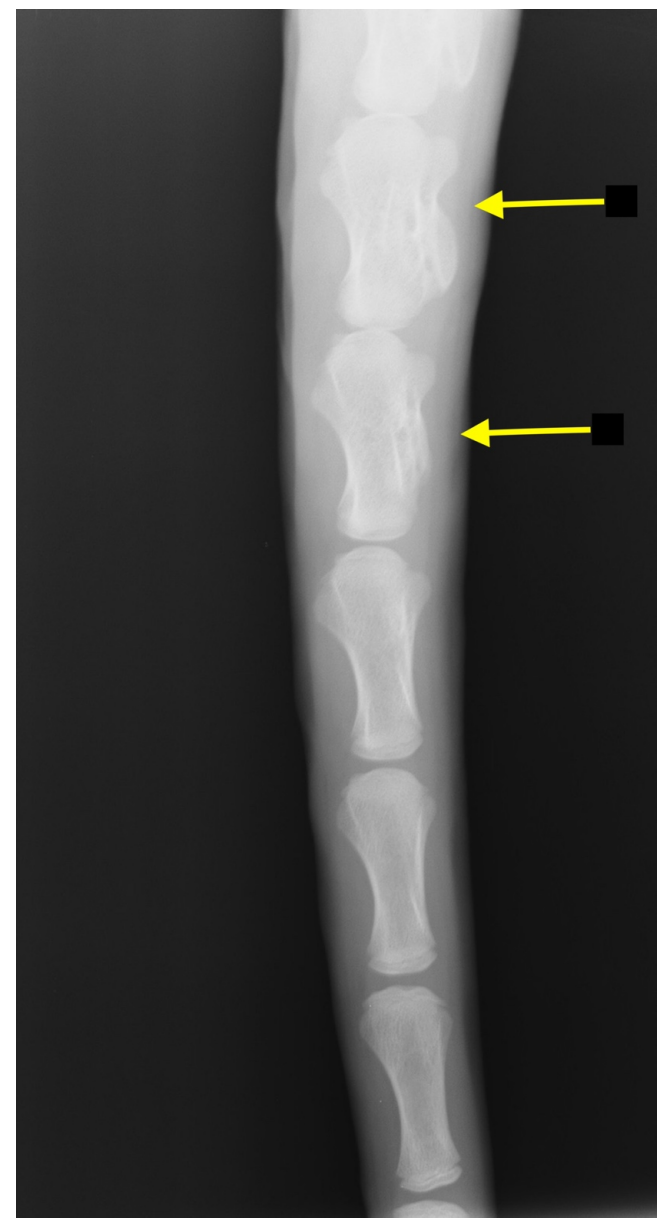

Figure 5. Example of morphological alterations (calcifications) in coccygeal vertebrae of Nellore cattle.

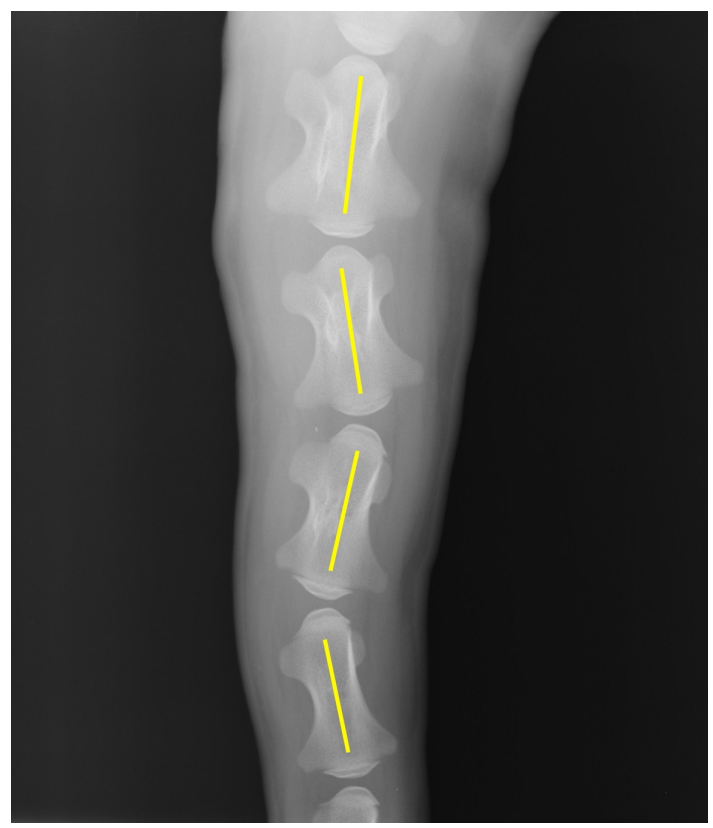

Figure 6. Example of deviation with loss of alignment of the coccygeal vertebrae in Nellore cattle. 
can lead to permanent disability, death or euthanasia [18] [19]. External impacts may result in fracture, subluxation, vertebral dislocation, hemorrhage, hematoma, spinal edema, compressive lesions, and spinal or associated root laceration, which result in different degrees of neurological dysfunction [20] [21]. However, none of the evaluated cattle showed such lesions.

\section{Conclusion}

It is concluded that modern vaquejada races, which meet the current rules such as the use of the tail protectors and punctuation bands with soft sand mattresses, can prevent injuries to the locomotor system or other tissues evaluated here in cattle. Radiographically, it can be concluded that the occurrence of lesions in the tail of cattle is very low, where most of them preexisting as a race of cattle, indicating that these injuries appear throughout the life and may not be diagnosed. The radiographic findings in the tail, represented by reduction of the intervertebral space and areas of subcutaneous radiolucency, suggest technical artifacts derived from the manipulation of the tail for proper positioning to perform the tests in the condition of retention in the brete. Finally, all the oxen used had natural behavior and did not present mental suffering within 24 hours after the end of the vaquejada test.

\section{Conflicts of Interest}

The authors declare no conflicts of interest regarding the publication of this paper.

\section{References}

[1] Associação Brasileira de Vaquejada-ABVAQ (2021) Regulamento Geral de Vaquejada. https://www.abvaq.com.br/regulamento

[2] Pellegrini, M.M., Pellegrini, C.M., Gallo, M.A., Foz-Filho, R.P.P. and Zoppa, A.L.V. (2017) Avaliação radiográfica da coluna cervical de bovinos que participaram de prova de laço em duplas. Pubvet, 11, 581-586. https://doi.org/10.22256/pubvet.v11n6.581-586

[3] MAPA-Ministério da Agricultura, Pecuária e Abastecimento (2017) Portaria N ${ }^{\circ}$ 1.781, de 14 de Agosto de 2017.

https://www.gov.br/agricultura/pt-br/assuntos/inspecao/produtos-animal/avaliacao -de-inovacoes-tecnologicas/arquivos/in-sda-30_2017-anexo-dou_16-08-2017_pag-2 pdf

[4] Lesimple, C. (2020) Indicators of Horse Welfare: State-of-the-Art. Animals, 10, 294. https://doi.org/10.3390/ani10020294

[5] Rebhum, W.C. (2000) Doenças Neurológicas: Doenças do Gado Leiteiro. Rocca, São Paulo.

[6] Douglas, S.W. and William, H.D. (1970) The Vertebral Column and Rib Cage. In: Veterinary Radiological Interpretation, Lea \&Febiger, Philadelphia, 72-75.

[7] Morgan, J.P. (1972) Vertebral Column. In: Radiology in Veterinary Orthopedics, Lea \& Febiger, Philadelphia, 219-300. 
[8] Walker, M.A. (1998) The Vertebrae. In: Thrall, D.E., Ed., Textbook of Veterinary Diagnostic Radiology, 3rd Edition, W. B. Saunders, Philadelphia, 81-88.

[9] Mellor, D. (2017) Operational Details of the Five Domains Model and Its Key Applications to the Assessment and Management of Animal Welfare. Animals (Basel), 7, 60. https://doi.org/10.3390/ani7080060

[10] Oehm A., Knubben-Scweizer, G., Rieger, A., Stoll, A. and Hartnack, S. (2019) A Systematic Review and Meta-Analyses of Risk Factors Associated with Lameness in Dairy Cows. BMC Veterinary Research, 15, Article No. 346 https://doi.org/10.1186/s12917-019-2095-2

[11] Newcomer, B.W. and Chamorro, M.F. (2016) Distribution of Lameness Lesions in Beef Cattle: A Retrospective Analysis of 745 Cases. Canadian Veterinary Journal, 57, 401-406.

[12] Silveira, J.A.S., Silva, N.S., Bomjardin, H.T., Reis, A.S.B., Oliveira, C.M.C., Duarte, M.D. and Barbosa, J.D. (2018) Estudo epidemiológico e clínico de afecções podais em bovinos de corte manejados extensivamente no sudeste do Pará. Pesquisa Veterinária Brasileira, 38, 367-373. https://doi.org/10.1590/1678-5150-pvb-4411

[13] Gama Filho, R.V., Fonseca, F.A., Ueno, V.G., Fontes, R.S., Quirino, C.R. and Ramos, J.L.G. (2007) Sazonalidade na dinâmica folicular ovariana e produção embrionária em novilhas da raça Guzerá. Brazilian Journal of Veterinary Research and Animal Science, 44, 422-427. https://doi.org/10.11606/issn.1678-4456.bjvras.2007.26607

[14] Shiota, A.M., Santos, S.F., Nascimento, M.R.B.M., Moura, A.R.F., Oliveira, M.V. and Ferreira, I.C. (2013) Parâmetros fisiológicos, características de pelame e gradientes térmicos em novilhas nelore no verão e inverno em ambiente tropical. Bioscience Journal, 29, 1687-1695.

[15] Constable, P., Hinchcliff, K., Done, S. and Grünberg, W. (2021) Clínica Veterinária-Um Tratado de Doenças dos Bovinos, Ovinos, Suínos e Caprinos. Guanabara Koogan, Rio de Janeiro.

[16] Feitosa, F.L. (2016) Semiologia veterinária-A arte do diagnóstico. Editora Roca, São Paulo.

[17] Owens, J.M. and Biery, D.N. Principles of Radiographic Interpretation. In: Owens, J.M. and Biery, D.N., Eds., Radiographic Interpretation for the Small Animal Clinician, Williams \& Wilkins, 9-11.

[18] Bergman, R. (2000) Spinal Cord Injury. Veterinary Medicine, 95, 845.

[19] Arias, M.V.B., Severo, M.S. and Tudury, E.A. (2007) Trauma medular em cães e gatos: revisão da fisiopatologia e do tratamento médico. Semina Ciências Agrárias, 28, 115-134. https://doi.org/10.5433/1679-0359.2007v28n1p115

[20] Bagley, R.S., Harrington, M.L., Silver, G.M., Cambridge, A.J., Connors, R.L. and Moore, M.P. (1999) Exogenous Spinal Trauma: Clinical Assessment and Initial Management. Compendium Continuing Education for Veterinarians, 21, 11381144.

[21] Grasmueck, S. and Steffen, F. (2004) Survival Rates and Outcomes in Cats with Thoracic and Lumbar Spinal Cord Injuries Due to External Trauma. Journal of Small Animal Practice, 45, 284-288. https://doi.org/10.1111/j.1748-5827.2004.tb00236.x 